\title{
MODERNIZATION AND GLOBALIZATION IN THE AFTERMATH OF THE MASS MEDIA
}

\author{
Sobia Usman ${ }^{1}$, Usman Farooq ${ }^{2}$, Muhammad Umair Chaudhary ${ }^{3^{*}}$
}

${ }^{1}$ Assistant Professor, Department of Media Science, Ilma University Karachi, Pakistan; ${ }^{2}$ Department of Media Studies, The Islamia University of Bahawalpur, Pakistan; ${ }^{3 *}$ Assistant Professor (IPFP - Fellow), Department of Mass Communication, Virtual University, Lahore, Pakistan.

Email: *umair.chaudhary@vu.edu.pk

\author{
Received on $5^{\text {th }}$ February 2021, Revised on $25^{\text {th }}$ February 2021, Published on $3^{\text {rd }}$ March 2021
}

\begin{abstract}
Purpose of the study: This research is a humble effort to ascertain what constitutes the connection between our prevailing societies, culture, and mass media; it is an effort to delve into the realm of the circumstances and conditions that cause the three of them to be intertwined.

Methodology: Qualitative research method has been used to analyze \& explore the confusing and increasing connection between predominant societies and mass media.

Main Findings: The cultural effervescence, richness, and vibrancy of the globe are at stake and this cannot be further ignored. Because of the unrelenting cultural promotion of the dominant powers by the use of the media in the developing world, the younger generation is blissfully unaware of the rich local cultures, traditions, and values that their predecessors held in these countries.
\end{abstract}

Application of the study: The present study may be applied to understand the consequences of Mass media after its advancement \& globalization.

Keywords: Society, Culture, Mass Media, Media Ownership, Modernization, Globalization.

\section{INTRODUCTION}

Society is generally defined as a collection of people who live together and rely on each other for their survival and wellbeing (Ayoroa et al., 2010). The current global system is made up of a wide range of different countries and cultures. One of the most popular definitions of a society is that it is an organized collection of people who live and work together to ensure the group's long-term existence (Astiz et al., 2002). There may be several societies inside a single country, which is why not all societies are countries. " Every person's engagement in their local community's institutions is just as important as their social membership in the world system. Every member of society has some kind of connection to the family, religion, economics, education, and state institutions (Billington et al., 1992). It's the way these institutions work that has a direct impact on people's lives, but it may also have an impact on people's lives in various ways based on their color, ethnicity, class, or gender, for example. These characteristics are regarded to be the basic structuring principles that social institutions work under.

At some point in the late $19^{\text {th }}$ century, anthropologists began to formulate a modern definition of culture: "that complex whole consisting of knowledge, belief, art, law, morals, customs, and any other capabilities acquired by man as a member of a society." Sir Edward Taylor of the University of Cambridge provided the first comprehensive definition of culture in his writing in 1871.

Rather than being a part of our genetic make-up, everything about our culture is something we acquire. Humanity's'social heredity' is referred to by Ralph Linton, an anthropologist. Social scientists generally agree that the best way to learn about one's culture is to immerse oneself in it from an early age, and this process of cultural transmission is referred to as "enculturation."(Leach, 1982). The propagation and learning of culture are greatly aided by the use of a common language.

Financial markets were first developed, many business and lifestyle principles were shared by the primary participants. Using leisure activities as an example, he said that there is a strong link between the two. According to some other academics, the rise in global consumption and consumerism, as well as the diffusion of popular culture (e.g., Madonna or Michael Jackson's most recent songs), is the foundation of cultural globalization (Featherstone, 1990).

In this digital age we have communication that reaches large numbers of people/audiences in the blink of an eye, such as social media, television, newspapers, and magazines and radio, etc. these are referred to as the mass media. To further understand the media, researchers certainly claim that mass media are those forms of media that are designed to be consumed by a large portion of the world's population and are also a direct present-day medium for mass communication. The media is society's fourth estate, as well as the cornerstone of every democratic government, so please keep that in mind. People and society as a whole see it as a means of expressing themselves and defending their interests (Tylor, 2004).

It is commonly understood that the Mass media is intended to be played before a large audience. Television and radio are two examples of broadcast media; newspapers and magazines are examples of print media. Today, it is clear that mass- 
media organizations must maintain an online presence to take advantage of the widespread availability of the Internet in many parts of the globe. It is also referred to as the "mainstream media" since it tends to focus on news that is believed to be of interest to a broad audience (Kellner, 2011).

In the present day and age, people around the world rely on mass media for their daily dose of news and entertainment. Globally the mass media is a huge Trillion Dollar industry. The understanding of the consumption patterns of the mass media is usually a key to the understanding of the dynamics of a society's culture. This is why we find that the field of media studies is so enormous and involves people from all walks of life. The process of watching, reading, and subsequently interacting with a nation's mass media will provide valuable hints into how the people of that particular nation think. This will be all the truer especially if a varied combination of the mass media sources in vogue are perused (Thussu, 2006 ; Ott et al., 2010).

The researchers have witnessed a flurry of activity in the field of the transmission abilities of the mass media in the last few decades. After the telegraph, we had radio, newspapers, magazines, television, and now the internet. As a society, we are increasingly reliant on both information and a wide range of means of communication to function this allows us to move in the right direction and maintain our life balance by staying in touch with our loved and near ones and abreast of the activities in the society we live in. It has been seen that as a general rule of the thumb people have allowed the Media to be the opinion-forming authority in their lives in the fields of information, entertainment, news and, education (Thompson, 1995; Kellner, 2011).

Whatever we think of mass media, on the whole, it's all about invention, novelty, and modernity, which is always changing and creating new methods to speed up the process of subsisting on the planet, as we know it.

\section{Research Questions}

1. How have economic, political, and social factors affected patterns of culture in our society?

2. How can we develop media outlets and communications to be more culture-inclusive?

3. What effect does the exposure to different forms of social media have on the recipient's perception of their indigenous way of living?

\section{Objectives of the Research}

1. To make an effort to understand what is the connection between our prevailing societies, culture, and mass media.

2. To delve into the realm of the circumstances and conditions that cause the three of them to be intertwined.

3. To explore the explosive effects of the mass media on our culture and society and the negativity and positivity of these elements.

4. To define multiculturalism and assert the value of the different cultures which are co-existing within society.

\section{LITERATURE REVIEW}

Burlacu et al.(2018) describe that some researchers see globalization as a reality, while others see it as a term used to describe the present status of the international economy. Many people think of it as a full uniformity, while others see it as a variation in proportions based on universal principles. Globalization's benefits and drawbacks have been examined in both literary and international contexts, as well as the good and negative consequences of the phenomena.

Ergashev \& Farxodjonova (2020) discuss that the process of globalization is considered to be a fact. Its effect on national culture, both good and harmful. This rule of law is meant to protect the national identity of every country that chooses to express itself via a national tradition that incorporates and corresponds to its own unique national culture. Contrary to popular belief, it is essential to grow, acquire wealth, and become more contemporary. There are increasing pressures on national cultures as a result of globalization's progress.

According to Destek (2020) rising general globalization, economic globalization, and social globalization all increase carbon emissions, but increasing political globalization decreases environmental pollution.

Shermanov (2021) argued that globalization facilitates the interchange of knowledge, technology, and scientific and technological advancements amongst individuals from various nations, hence reducing national, religious, and cultural disparities. There are many ways in which it may be used, from the study of other cultures and traditions to the building of international diplomatic connections to the tracking of political processes. In addition, it promotes the interests of organizations with harmful views in various ideological reflections, disturbing society and producing social instability. People's mobility, activity, mental condition, as well as the political governance of society, the social situation, and the growth of legal awareness, are strongly linked to the essence of globalization.

Bennett (2016) states that there is an objective culture, which focuses on the institutional characteristics of a culture, and a subjective culture, which focuses on the worldview of individuals in a society. 
Giddens (2010) coined Time-space instantiation and refers it to the contemporary communication-induced separation of time and space. Global issues, such as floods in Thailand or Indonesia, the famine in Ethiopia or the tsunami in Japan, and major sporting events like the World Cup or the Olympics, have a global dimension. Global cultural homogeneity has been facilitated by the development of international economic, political, and social bodies such as the United Nations (UN), the World Health Organization (WHO), the United Nations Development Program (UNDP), the International Monetary Fund (IMF), and the World Bank.

According to Ayoroa et al. (2010), it seems that globalization is based on the capitalist economic heritage, which includes free markets, private ownership, open and free decision-making, the pricing mechanism, and competition.

Other creative items that excite and amuse people such as music, literature, visual arts, and film are included in Cowen et al.'s (2012) definition of culture. As a result, some communities exploit their culture as a commercial label to generate new items.

German scholar Goethe, on the other hand, called for a global civilization based on world literature (Weltlitertur). Cultural industries began to emerge in the twentieth century as communication technology advanced and spread seamlessly across national boundaries.

According to Appadurai (2010), the process of Heterogenization causes a more inward-looking world because of the deepening of flows among cultures. As a result, local cultures are constantly evolving and reinventing themselves as a result of global influences and circumstances.

Furthermore, according to Tomlinson (2012), globalization makes people aware of the many varied national cultures that exist across the globe. As a result, globalization enhances national cultures rather than weakens them.

Appadurai (2010) and Pieterse (2015) contend that cultural homogeneity is overly simple, while certain cultures have shown that they can adapt to or reject foreign influences. Rather than a monolithic cultural homogeneity, intercultural encounters foster cultural hybridity. With globalization comes a creative synthesis of global and local cultural characteristics.

Ritzer \& Degli Esposti (2020) describe that local cultures may be changed by more strong cultures or even a global culture via the process of homogenization, which is also known as convergence. Global culture, Americanization, and the McDonaldization hypothesis are all examples of this perspective's influence. On the other hand, the idea of global culture is debunked by Smith et al., (2013) in his 2003 paper.

Pravdová (2019) portrays that the widespread use of the Internet has altered many aspects of daily life, including the field of journalism. Communication between individuals, the dissemination and consumption of information, media genre features, and editorial offices are all experiencing substantial changes owing to the convergence process. Convergence as a concept has been established and several sorts of convergences have been outlined using the example of Kazakhstan's mass media. The primary sources of information for the study were Kazakhstan's national and provincial news websites, newspapers, and radio stations.

Iwabuchi (2019) explains that the trend of globalization has greatly accelerated the movement of people, wealth, and information across national borders. Affect-driven capabilities in digital communication technology and social media encourage these inclinations. Cultural mixing and hybridized identities, transnational conversation, as well as cosmopolitan awareness have been attributed to globalization's contempt for national boundaries. However, these changes do not inherently undermine national imaginations and country-centered frameworks, since they have further increased mediated collectivities outside and beyond the nation through digital communication technologies. The emergence of new forms of cross-border communication, trade, and conflict as a result of globalization and digitization has brought attention to the importance of national boundaries.

\section{METHODOLOGY}

This research paper has made a humble endeavor using qualitative narrative research to explore the perplexing and everincreasing connection between our prevailing societies, culture, and mass media. Thus, consequently, it may enhance the probability of increasing the understanding of the impact social interactions may have on our Culture. When researchers write about their own experiences, they are engaging in narrative research, which is the process of gathering and evaluating such stories. Narrative approaches are often used by researchers to study problems with personal experiences beyond the boundaries of a questionnaire, providing insight into decisions involving how the impact of social media can be measured on our prevailing culture. This can help guide us on how media being delivered to the public can be developed and provided more constructively. Definitions of narrative research, examples of published research using narrative methods in Media Studies have been employed. According to a recent survey of the sociological, anthropological, and psychological literature, narrative methodologies are a useful study tool for figuring out how Social Media affects Culture. Data was collected after going through related studies conducted on the subject as well as thoroughly browsing the available literature on hand. 


\section{FINDINGS}

\section{Combination of the Mass Media, Culture and Society}

Individuals' behaviors are understandable to other members of their community thanks to a shared set of values, beliefs, perceptions, and behavioral norms known as culture. Predicting how others will respond and react appropriately is made easier by this kind of analysis.

Societies may be described as a group or groups of interdependent individuals who share a similar land area, language, and culture and work together to ensure their survival and well-being. The interdependence of these people may be observed in their familial ties, economic systems, communication networks, and defense systems. This shared identity is also the glue that binds them together. Anthropologists examine both culture and society since they are so intertwined. Without a civilization, there would be no culture. On the other hand, no human society has yet been found to be devoid of culture.

Working people may be "proud, envious, and pugnacious" without experiencing "alienation," "depression," or any other prevalent maladies of our own cruel and civilized way of existence," according to this quote. Cultural collapse occurs when conventional methods of coping fail and individuals feel powerless to influence their own lives in their own cultures, resulting in the appearance of these symptoms. Maintaining a group's well-being is the primary goal for every culture. This means it may be considered effective if it ensures the long-term viability of a society in a manner that its people find satisfying. There is the chance that certain people's interests will be better served than those of others in a community, which complicates issues. Consequently, one group in a community may find great satisfaction in a culture that is less so for another.

Culture is transmitted mostly via the media. Television shows depict a wide spectrum of acceptable and undesirable behaviors and beliefs, such as race or ethnicity, class, gender, age, physical and mental aptitude, and sexual orientation. The structure of the shows sometimes encourages viewers to laugh at, detest, or denigrate civilizations that are different from the dominant ones in the US. Pakistani immigrants are often shown as naive convenience store proprietors and puzzled taxi drivers on The Simpsons. The Arabs are depicted as being filthy rich with a low IQ and a large appetite for women. The Chinese are shown to be a race that is physically less endowed with a flair for strange food.

The interests of key societal power groups, companies, and the affluent are reflected in news programming. Corporate advertising is the principal sponsor of television and radio programs, which in turn is controlled by large corporations. No matter how necessary, safe, or useful a product may be, ads on television cultivate a materialistic consumer mindset. Defining and enticing people to buy products and services is the lifeblood of capitalism, and advertising plays a key role in creating this culture. It's easier for producers of television shows to promote ideals and conventions that go against the grain of corporate culture when they aren't dependent on corporate sponsors.

\section{The Modernization \& Globalization of the West and its far-reaching Consequences}

Modernization is one of the most often used expressions to describe today's social and cultural shifts. Worldwide political and socioeconomic development is best described as an all-encompassing, global process in which emerging countries acquire some of the cultural elements common to Western industrial civilizations. Modernization is derived from the Latin word modo ("now"), which means "in the here and now." To be "modern" is to become like the United States and other industrialized countries, with the connotation that not doing so is to be backward, inferior, and need to be better individuals. Unfortunately, the word "modernization" continues to be utilized in such a widespread way. Because we're trapped with it for the time being, the best we can do is acknowledge its terrible one-sidedness while using it.

There are four distinct stages in the modernization process, and one of them is the advancement in technical innovation. For several centuries, traditional knowledge and practices have been replaced by scientific ones, mostly from the industrialized West, in the process of modernization. Farmers are increasingly turning to commercial farming rather than raising crops and livestock for their consumption, and they are increasingly dependent on the cash economy and global markets to sell and buy farm products. Another aspect of agricultural development is the shift from subsistence farming to commercial farming. Industrialization is a third sub-process, with a larger reliance on tangible types of energy, such as fossil fuels, to power machinery. " Human and animal power, as well as handicrafts in general, fall in importance. Population migrations from rural areas to cities constitute the fourth sub-process of urbanisation. All processes are connected, but there is no definite sequence of manifestation for the sub-proceurbanizationr adjustments are expected to come as modernization progresses. Political parties and some kind of electoral machinery are common in the political arena, as is the formation of an administrative bureaucracy. Institutional learning options proliferate, literacy rises, and an indigenous educated elite is formed in formal schooling. The traditional ideas and practices of religion are less relevant in many aspects of cognition and conduct because they are indeterminate. Traditional kinship rights and responsibilities have been amended, if not abolished, particularly when it comes to distant relatives. Ascribed status becomes less significant when personal performance takes precedence in social mobility, where social happiness plays a role.

People who live in modern state societies are influenced by modernization. Political and economic transformations are taking place throughout the so-called impoverished globe, from Africa to Asia to South and Central America and everywhere in between. A wide range of technological breakthroughs is changing the way people live throughout Europe 
and North America as a result of innovations in industrial production, transportation, and communication. "Globalization" refers to this worldwide process of rapid modernization in which all regions of the Earth are linked in a massive interdependent and all-encompassing system.

The current buzzword is Globalization which is thought to be a notion that has seized the imaginations of students, workers, teachers, businessmen, and politicians alike. As we see the world around us become increasingly fragmented by the specialized interests of the powers to be, The fact that it's gotten more global at the same time is something we have to accept. Multifaceted processes such as Globalization, which is a multi-faceted collection of social and economic processes, are collapsing in favor of developing global social relationships rather than the physical limits and structural regulations that had previously supported the nation-state. On the other hand, we must accept that globalization itself is multidimensional, the most important dimension which has been seen forthcoming from it is economic globalization. This economic globalization is reminiscent of the colonization of the third world by the first world in the last three centuries. The spread of capitalism has tremendously fueled the rise of multinational corporations who wish to profit from untapped "global markets." By global markets here we refer to the developing countries that provide precious raw material to these corporations in the shape of cheap human resources and material as well. Hence, these corporations then aggressively support the free-trade policies that remove barriers in the way of their economic growth such as trade tariffs between national and international markets. The trend of globalization gives chances for the mass media, which are virtually solely owned and controlled by multinational businesses today, to transfer their goods from their culture to distant local markets thereby increasing revenues. Fears about cultural imperialism, in other words, the imposition of one culture's ideals on another, are the current concerns. However, we are seeing that local markets are influencing the goods and thinking of the corporations who are targeting them, leading to concerns that the cultural distinction is being erased in favor of a single hybridized culture. This is ideal for the multinational corporations now in charge of the global economy.

The human race has always been on the go. Modern transportation has made it possible for more people to go further and quicker than ever before. From print media to telegraph and phone to the internet, new technologies have made it possible to communicate with more people more quickly and over larger distances than ever before. The movement of people, goods, and ideas throughout the world has a significant influence on cultural evolution. Since the mid-1900s, there has been a widespread assumption that the globe would eventually become a unified, homogenous civilization. According to this theory, technical advancements in communication, transportation, and commerce have resulted in people throughout the globe watching the same shows, reading the same newspapers, eating the same foods, and dressing in the same fashions. 175 million individuals (2.5 percent of the global population) today reside outside their home nations, not as refugees but as migrants who make a livelihood in one place while maintaining their national identity another.

\section{DISCUSSION / ANALYSIS}

This research is a humble effort to ascertain what constitutes the connection between our prevailing societies, culture, and mass media; it is an effort to delve into the realm of the situations and circumstances that cause the entangled with each other (Dines \& Humez, 2003). Explosive effects of the media on our society and culture are explored and the negativity and positivity of these elements have been taken into account to understand how the diversity of cultures is being threatened in this regard (Tylor, 2004). The relationship between the growing phenomenon of globalization, modernization of media, and the way it has led to the pervasive and persistent cultural invasion by the dominant powers that are presently in control of the world of Media. As a result of this cultural invasion via mass media, the globe's underdeveloped nations are losing their unique cultural heritage, particularly in the developing world. The effervescence of cultural life, richness, and vibrancy of the globe is at stake here and this cannot be further ignored. (Straubhaar, 2017). The younger generations of underdeveloped nations are blind to their rich local cultures, customs, and values because of the persistent cultural promotion of the dominant powers via the use of the mass media in these countries.

\section{CONCLUSION}

Mass media have gone from being just one of many institutions in our cultural environment to the basic foundation of that environment in the transition to post-modernity. It is distressing to realize that the less important mass media are to social life the farther back in history one goes, the more central are other social institutions like the family, the worship sites, the school, and the state. They have been obscured by the media's biased perspective, which has made these social structures more difficult to see and understand Today, the media have supplanted families as caregivers, religious institutions as arbiters of cultural norms, schools as educational institutions, and the state as public agenda-setters.

Everyone knows the concept of global culture may have a degree of appeal, in that it might reduce the likelihood of clashing ideas and misunderstandings that have often led to violence and even full-scale conflicts. While this prediction is met with skepticism by anthropologists, who believe that diverse worldviews will continue to exist even as mainstream media undergoes a radical transformation, it is not without precedent. One would argue that the likelihood of clashing ideas grows, as seen by the severely divergent opinions among European countries long allied to the United States about its choice to attack Syria, Iraq, Afghanistan, and impose sanctions on Iran. Traditional cultures may not be capable of adapting quickly enough in the future to a more globalized society, as has been claimed by others.

As a society, we must recognize that a single global culture is not necessarily the destiny of humanity. Some of us believe that as a result of globalization, ethnic groups will become more patriotic, highlighting their distinct cultural history while 
simultaneously emphasizing their contrasts with one another. But there is one approach to counteract the forces of divisiveness in pluralistic or multi-ethnic society based on mutual respect and tolerance for cultural diversity. According to the official policy or ideology of multiculturalism in a given nation, all people are expected to embrace the rights of others to freely express their own beliefs as well as to respect the rights of others who are different from them. In this way, it is possible to keep society dynamic by enabling a wide range of cultures to thrive.

\section{CONFLICT OF INTEREST AND ETHICAL STANDARDS}

It is clarified that there exists no conflict of interest with any organization and it is assured that no unethical practices have been followed during the study.

\section{AUTHOR'S CONTRIBUTION}

All of the authors worked together to complete this study. The authors of this research study have also contributed under their assigned responsibilities. Dr. Sobia Usman was entrusted with the task of collecting the data on the subject. Dr. Usman Farooq was responsible for collating the data and then discussions and evaluations were held in presence of Dr. Muhammad Umair Chaudhary to bring out the findings and discussions.

\section{REFERENCES}

1. Appadurai, A. (2010). Disjuncture and difference in the global cultural economy 1990. Cultural Theory: An Anthology, 282-295. https://doi.org/10.1177/026327690007002017

2. Ayoroa, P., Bailey, B., Crossen, A., \& Geo-JaJa, M. A. (2010). Education in China: the urban/rural disparity explained. In Globalisation, ideology, and education policy reforms (pp. 89-113). Springer, Dordrecht. https://doi.org/10.1007/978-90-481-3524-0_7

3. Bennett, A. (2016). The festivalization of culture. Routledge.

4. Billington, R., Strawbridge, S., Greensides, L. \& Fitzsimons, A. (1992). Culture And Society: A Sociology of Culture (2nd ed.). MacMillan Press Ltd. https://doi.org/10.1007/978-1-349-21518-8

5. Burlacu, S., Gutu, C., \& Matei, F. O. (2018). Globalization-pros and cons. Calitatea, 19(S1), 122-125.

6. Cowen, P., Harrison, P., \& Burns, T. (2012). Shorter Oxford textbook of psychiatry. Oxford university press. https://doi.org/10.1093/med/9780199605613.001.0001

7. Destek, M. A. (2020). Investigation on the role of economic, social, and political globalization on environment: evidence from CEECs. Environmental Science and Pollution Research, 27(27), 33601-33614. https://doi.o $\mathrm{rg} / 10.1007 / \mathrm{s} 11356-019-04698-\mathrm{x}$

8. Dines, G., \& Humez, J. M. (2003). Gender, race, and class in media: A text-reader. Sage.

9. Ergashev, I., \& Farxodjonova, N. (2020). Integration of national culture in the process of globalization. Journal of Critical Reviews, 7(2), 477. https://doi.org/10.31838/jcr.07.02.90

10. Featherstone, M. (Ed.). (1990). Global culture: Nationalism, globalization and modernity (Vol. 2). Sage.

11. Giddens, A. (2010). The rise and fall of New Labour. New Perspectives Quarterly, 27(3), 32-37. https://doi.org/10.1111/j.1540-5842.2010.01179.x

12. Kellner, D. (2011). Cultural studies, multiculturalism, and media culture. Gender, race, and class in media: $A$ critical reader, 3, 7-18.

13. Iwabuchi, K. (2019). Globalization, Digitalization, and Renationalization: Some Reflections from Japanese Cases. Situations, 12(1), 1-2.

14. Leach, E. (1982). Social Anthropology. Glasgow: Fontana Paperbacks. pp.-124

15. Ott, Brian L. \& Mack, Robert L. (2010). Critical Media Studies: An Introduction. West Sussex: Philosophy, Religion, Art, and Custom. New York: Gordon Press.pp.-177

16. Pieterse, J. N. (2015). Globalization and Culture: Global Mélange. Rowman \& Littlefield.

17. Pravdová, H. (2019). Trends in Media Globalization and Oligarchization. European Journal of Science and Theology, 15(3), 109-119.

18. Ritzer, G., \& Degli Esposti, P. (2020). Creative Destruction and Cultural Lag in the Digital Age. Sociology Between the Gaps: Forgotten and Neglected Topics, 5(1), 5.

19. Shermanov, E. (2021). Role of mass media in the formation of participatory education in the context of globalization. Emergent: Journal of Educational Discoveries and Lifelong Learning (EJEDL), 2(06), 77-79.

20. Smith, P. B., Fischer, R., Vignoles, V. L., \& Bond, M. H. (2013). Understanding social psychology across cultures: Engaging with others in a changing world. Sage.

21. Straubhaar, J. D. (2007). World television: From global to local. SAGE publications.

22. Thompson, J. B. (1995). The media and modernity: A social theory of the media. Stanford University Press.

23. Thussu, D. K. (2006). Media on the move: Global flow and contra-flow. Routledge. https://doi.org/1 $\underline{0.4324 / 9780203001233}$

24. Tomlinson, M. (2012). Graduate employability: A review of conceptual and empirical themes. Higher Education Policy, 25(4), 407-431. https://doi.org/10.1057/hep.2011.26

25. Tylor, E.B. (2004). Primitive Culture: Researches into the Development of Mythology. Wiley-Blackwell. pp.-11. 